\title{
Discussion of Available Methods to Support Reviews of Spent Fuel Storage Installation Cask Drop Evaluations
}

\author{
M. Witte
}

March 28, 2000

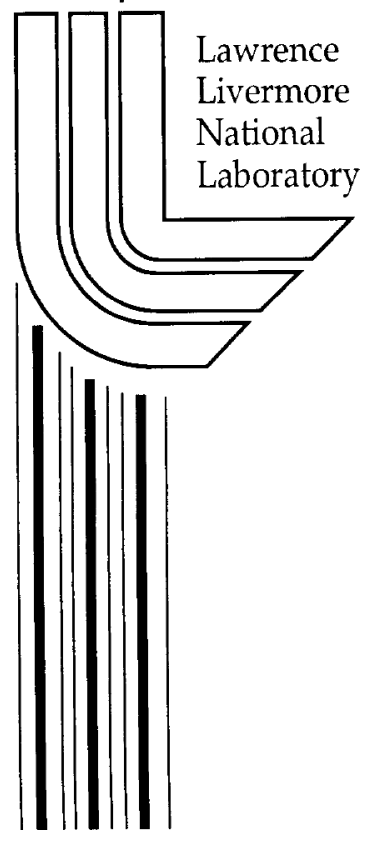




\section{DISCLAIMER}

This document was prepared as an account of work sponsored by an agency of the United States Government. Neither the United States Government nor the University of California nor any of their employees, makes any warranty, express or implied, or assumes any legal liability or responsibility for the accuracy, completeness, or usefulness of any information, apparatus, product, or process disclosed, or represents that its use would not infringe privately owned rights. Reference herein to any specific commercial product, process, or service by trade name, trademark, manufacturer, or otherwise, does not necessarily constitute or imply its endorsement, recommendation, or favoring by the United States Government or the University of California. The views and opinions of authors expressed herein do not necessarily state or reflect those of the United States Government or the University of California, and shall not be used for advertising or product endorsement purposes.

This work was performed under the auspices of the U.S. Department of Energy by the University of California, Lawrence Livermore National Laboratory under Contract No. W-7405-Eng-48.

This report has been reproduced directly from the best available copy.

Available electronically at http://www.doe.gov/bridge

Available for a processing fee to U.S. Department of Energy and its contractors in paper from

U.S. Department of Energy

Office of Scientific and Technical Information

P.O. Box 62

Oak Ridge, TN 37831-0062

Telephone: (865) 576-8401

Facsimile: (865) 576-5728

E-mail: reports@adonis.osti.gov

Available for the sale to the public from

U.S. Department of Commerce

National Technical Information Service 5285 Port Royal Road Springfield, VA 22161

Telephone: (800) 553-6847

Facsimile: (703) 605-6900

E-mail: orders@ntis.fedworld.gov

Online ordering: http://www.ntis.gov/ordering.htm

OR

Lawrence Livermore National Laboratory

Technical Information Department's Digital Library

http://www.llnl.gov/tid/Library.html 


\section{DISCUSSION OF AVAILABLE METHODS TO SUPPORT REVIEWS OF SPENT FUEL STORAGE INSTALLATION CASK DROP EVALUATIONS}

\section{Background and Scope}

Applicants seeking a Certificate of Compliance for an Independent Spent Fuel Storage Installation (ISFSI) cask must evaluate the consequences of a handling accident resulting in a drop or tip-over of the cask onto a concrete storage pad. As a result, analytical modeling approaches that might be used to evaluate the impact of cylindrical containers onto concrete pads are needed. One such approach, described and benchmarked in NUREG/CR-6608, ${ }^{1}$ consists of a dynamic finite element analysis using a concrete material model available in DYNA3 ${ }^{2}$ and in LS-DYNA, ${ }^{3}$ together with a method for post-processing the analysis results to calculate the deceleration of a solid steel billet when subjected to a drop or tip-over onto a concrete storage pad.

The analysis approach described in NUREG/CR-6608 gives a good correlation of analysis and test results. The material model used for the concrete in the analyses in NUREG/CR-6608 is, however, somewhat troublesome to use, requiring a number of material constants which are difficult to obtain. Because of this a simpler approach, which adequately evaluates the impact of cylindrical containers onto concrete pads, is sought.

Since finite element modeling of metals, and in particular carbon and stainless steel, is routinely and accurately accomplished with a number of finite element codes, the current task involves a literature search for and a discussion of available concrete models used in finite element codes. The goal is to find a balance between a concrete material model with a limited number of required material parameters which are readily obtainable, and a more complex model which is capable of accurately representing the complex behavior of the concrete storage pad under impact conditions. The purpose of this effort is to find the simplest possible way to analytically represent the storage cask deceleration during a cask tip-over or a cask drop onto a concrete storage pad.

This report is divided into three sections. The Section II provides a summary of the literature search on concrete finite element models. The Section III discusses commercial codes. The Section IV provides recommendations.

\section{Concrete Finite Element Modeling Methods Relevant To Cask Drop Evaluations: A Literature Search}

Akers, Stephen A. and Adley, Mark D., "Constitutive Models Used to Simulate Penetration and Performance of Concrete Targets," American Society of Mechanical Engineers, Pressure Vessels and Piping Division, PVP Vol. 325, July 21 26 1996. Author affiliation: U.S. Army Engineer Waterways Experiment Station.

This paper provides a description of two recently developed constitutive models, both Hybrid Elastic Plastic (HEP) models, which were added to the large strain Langrangian wave-propagation code EPIC. EPIC is a research finite element code developed by Alliant Techsystems. Inc. The models were developed to evaluate impact of semi-armor 
piercing projectiles onto concrete slabs. The models are used to fit both geomaterials such as sands, clays, silts, crushed rock and rock, and concrete. Quasi-static laboratory test data are required for the models, including stress-path and strain-path responses from uniaxial strain tests, a failure surface from triaxial shear tests, and a pressure-volume relationship from hydrostatic compression test data. The authors state that the enhanced model must be calibrated to special laboratory strain-path test data.

Test results used for benchmarking the model were not included in the paper because the results were classified as a critical technology. The authors did provide a comparison with other codes in the paper, and they stated that the models used overpredict the exit velocity for some cases, but that generally the results appeared good. Decelerations reported are larger than those reported in NUREG/CR-6608 by three orders of magnitude, primarily due to the higher impact velocity.

Applicability to cask impact: Applicable, except that needed material properties appear to be as extensive or more so than the properties required for the method used in NUREG/CR-6608.

Attaway, Stephen W.; Matalucci, Rudolph V.; Morrill, Kenneth B.; Malvar, L. Javier; Crawford, John E., "Enhancements to PRONTO3D to Predict Structural Response to Blast;" Sandia Draft copy dated October 15, 1999. Author affiliation: Attaway and Matalucci, Sandia National Laboratories, Albuquerque, NM; Morrill, Malvar, and Crawford, Kargozian and Case Structural Engineers, Glendale, CA.

A concrete model including reinforcement materials is described and benchmarked for blast loading of concrete structures. The model presented is a modification of a model used in DYNA3D, see discussion of Malvar, 1997 paper below.

Applicability to cask impact: Probably applicable. Concrete is subject to dynamic loading.

Attwood, G. J. and Butler, N., "Validation of Computer Modelling Techniques for Predicting the Impact Performance of Containers for the Transportation of Radioactive Materials," Proceedings of the Second International Conference on Structures Under Shock and Impact II June 1992, published by Computational Mechanics Publishers. Author affiliation: Impact Technology Department, AEA Reactor Services, Winfrith Technology Centre, Dorchester, Dorset, DT2 8DH, U.K.

Analyses using DYNA3D and experimental tests were made of the following drops:

1) Thick walled steel cask used for transporting spent nuclear fuel: $6 \mathrm{~m}$ corner drops onto a rigid target with full-scale half-length test and with $1 / 4.5$ scale test.

2) "Ruggedised" ISO type container, used for transporting radioactive waste (rectangular box-like container). These were quarter scale tests, impact simulated for unyielding and concrete targets. Information about the concrete target model is not included.

3) Steel-clad concrete package, used to transport decommissioning waste. Impact tests were conducted horizontally with an air gun. No actual results were provided, no 
material properties were provided. The concrete was modeled as a crushable foam material using compaction and yield surface properties stated to be "known."

Applicability to cask impact: Applicable, except that needed material properties and other information were not provided. I have attempted to contact authors via the Winfrith web site, 10/29/99. The authors have not yet responded to a request for more information.

Bhattacharya, Arun and Velinsky, Steven A., "Finite Element Implementation of the Microplane Theory for Simulating a Rigid Concrete Pavement-Vehicle Interaction," Mechanics of Structures and Machines, Nov. 1998. Author affiliation: University of California at Davis.

Bazant's microplane theory is applied for concrete pavement. Theory is discussed in paper for completeness. Material's constitutive laws are represented by a relation between stress and strain components on planes of various orientations. These planes may be imagined to represent damage planes or weak planes in the microstructure, such as contact layers between aggregate pieces in concrete.

Authors state "even the most advanced and widely used large scale codes, e.g., ABAQUS, ANSYS, and DYNA3D, have yet to provide a model of concrete or asphalt in its material library that could capture the constitutive response of pavement under dynamic loading, varying strain rates, or cyclic loading."

The paper discusses the methodology for implementing the microplane theory in ABAQUS. The authors claim that the method provides a substantial improvement over the most widely used pavement design software.

Applicability to cask impact: Probably not applicable because the goals are different. Their effort is to predict pavement damage due to long term cyclic pavement-vehicle interaction, rather than examining initial dynamic response of concrete due to impact.

Broadhouse, B.J., "DYNA3D Analysis of Cone Creek Formation due to Heavy Dropped Loads on Reinforced Concrete Floors," Proceedings of the Second International Conference on Structures Under Shock and Impact II June 1992, published by Computational Mechanics Publishers. Author affiliation: Impact Technology Department, AEA Reactor Services, Winfrith Technology Centre, Dorchester, Dorset, DT2 8DH, U.K.

The problem evaluated is the performance of reinforced concrete floors subjected to heavy dropped loads. Both analytical and experimental investigations are reported. The test object is a $2 \mathrm{~m} \times 2 \mathrm{~m} \times .3 \mathrm{~m}$ concrete panel, with reinforcing, which is supported around the perimeter only. The edge boundary conditions are most accurately described as fixed. The author describes a process of performing a sensitivity study with DYNA3D to determine which material parameters the model is sensitive to, and a "best" calculation was performed. The results of the calculation fairly closely match the experimental results for deflection time history plots. 
Applicability to cask impact: Applicable. Further information about the model parameters used, was requested from the author, see below for the response.

Broadhouse, B.J.; "The Winfrith Concrete Model in LS-DYNA3D," SPD/D(95)363, February 1995. Author affiliation: Structural Performance Department, AEA Technology, Winfrith Technology Centre, RD3 Risley, Warrington, Cheshire WA3 6AT, U.K.

John Duthie provided the report, since the author is currently retired from AEA Technology. Report describes a concrete model developed by the author, which may be used with LS-DYNA as a module, and is available for a contract fee from AEA. The concrete model uses smeared crack, smeared reinforcing steel and is available for the 8node single integration point brick element. A description is provided of the format and input required for the model to be used in LS-DYNA; no specific properties are provided. Limited results of an interesting analysis are given. While no comparison with test data is provided, an article by the same author listed above does provide limited test results for the same problem. The model uses Material Type 84, see discussion under LS-DYNA in Section III of this report.

Applicability to cask impact: Applicable, except that needed material properties and other information are not provided. The model would need to be more fully tested to conclude that it is appropriate for our case. Note that the model uses a Material Type (Type 84), which is not available in the version of LS-DYNA described in the May 1999 user's manual.

Carol, Ignacio; Prat, Pere C.; Bazant, Zdenek P.; "New Explicit Microplane Model for Concrete: Theoretical Aspects and Numerical Implementation;" International Journal of Solids and Structures, Vol. 29, No. 9, 1992. Author affiliation: Carol and Pratt, School of Civil Engineering, Technical University of Catalonia, Barcelona, Spain; Bazant, Department of Civil Engineering, Center for Advanced CementBased Materials, Northwestern University.

A microplane model, suggested in the early 1980's by Bazant and others is an approach that describes the triaxial behavior of concrete. This paper provides a theoretical description and a modular implementation in a computer code. Microplane was referred to from 1938 to the early 1980 's as the "slip theory," model which was changed to microplane because there is in fact crack damage and not just slip. Results of uniaxial and triaxial compression analyses are compared with other models and with test results. Fourteen parameters are required for implementation.

Applicability to cask impact: Possibly applicable. Model would need to be installed into an explicit FE dynamic code.

Cela, Juan Jose Lopez, "Analysis of reinforced Concrete Structures Subjected to Dynamic Loads with a Viscoplastic Drucker-Prager Model," Applied Mathematical Modeling, July 1998. Author affiliation: Universidad de Castilla-La Mancha, Ciudad Real, Spain. 
Behavior of reinforced concrete structures subjected to dynamic loads (impacts, explosions) is analyzed using a model developed by the authors and implemented in PLEXIS-3C, a general finite element code developed since 1986 by the French Commissariat à l'Energie Atomique (CEA-CEN Saclay) and by the European Commission (EC-JRC Ispra). A Drucker-Prager elastoplastic model is used for concrete. Only two parameters are required to define the yield surface and one more to define the flow rule. The Drucker-Prager criterion is characterized by a conical yield surface, and is a smooth approximation to the Mohr-Coulomb criterion.

Several sample problems are considered. The first is a simply supported concrete slab subjected to time dependent load. (However, actual case described is a constant load.) The second sample case is a concrete cooling tower subjected to a local external pressure intended to simulate impact. The third is a gas explosion in a reactor containment. No comparison to test data was performed.

Applicability to cask impact: Possibly applicable. Model would need to be tested for our loading conditions. This model could probably be used in DYNA.

Chen, E. P., "Numerical Implementation of a Brittle Damage Model and its Application to Concrete Slab Perforation," PVP-Vol. 343, Development, Validation, and Application of Inelastic Methods for Structural Analysis and Design, ASME 1996. Author affiliation: Material and Structural Mechanics Department, Sandia National Laboratories, Albuquerque, New Mexico.

Analysis of steel projectile with ogive nose impacting concrete slabs using LS DYNA2D. Concrete material properties (not sure which material model) were calibrated for test results published by another researcher and referenced in paper. Good agreement was reached. The basis of comparison was post-penetration velocity.

Applicability to cask impact: Marginally applicable. We do not even come close to penetrating the concrete; our model does not need to include removal of failed material.

Chen, E. P., "Continuum Damage Model for the Quasi-static Response of a CenterCracked Plain Concrete Panel in Tension," American Society of Mechanical Engineers, Applied Mechanics Division, AMD, Vol. 109, 1990. Author affiliation: Material and Structural Mechanics Department, Sandia National Laboratories, Albuquerque, New Mexico.

A continuum damage model is presented. Assumption is that material is permeated by an array of randomly distributed cracks that grow and interact with one another under tensile load. Model treats growth of cracks as an internal state variable that represents accumulation of damage in the material. The model was developed for quasi-static loading and has been implemented into SANTOS, a finite element code developed at Sandia for two dimensional quasi-static, large deformation problems.

Results for a cracked tensile panel analysis are presented. They are not compared explicitly with test results, but the author states that generally the comparison appears to predict observed characteristics. 
Applicability to cask impact: Possibly applicable. Since the model was developed for quasi-static loading further evaluation would be required to determine suitability in a dynamic code. It appears that four parameters are required.

Chen, William W. and Chang, Shih-Jung "Verification of Maximum Impact Force For Interim Storage for the Fast Flux Testing Facility," PVP-Vol. 330, Natural Hazard Phenomena and Mitigation, ASME 1996,

Impact analysis for a four-foot end drop of the Interim Storage Cask (ISC) for FFTF. ISC is a concrete cask used to store spent nuclear fuel. General Atomics performed the calculation with the ILMOD computer code. ILMOD calculates the maximum force developed by the concrete crushing. The maximum force, multiplied by a dynamic load factor, was used to determine the maximum g-load on the cask.

Independent analyses (both very simple and complex) were performed with ABAQUS and ANSYS to confirm calculations. The analyses using ABAQUS and ANSYS resulted in higher impact loads than the ILMOD code. Nevertheless, the ILMOD results (g-loads) were considered acceptable by the authors.

Applicability to cask impact: Probably not applicable. Method appears to be an unnecessary simplification of the analysis required. The authors state that the simplification is required due to limited computing resources; this is no longer the case for most users. Also, the results would be based on the selection of a dynamic load factor.

Cheng, H.; Dusseault, M. B.; "Deformation and Diffusion Behaviour in a Solid Experience Damage: a Continuous Damage Model and Its Numerical Implementation," International Journal of Rock Mechanics and Mining Sciences and Geomechanics Abstracts, December 1993. Author affiliation: Departments of Civil Engineering and Earth Sciences, University of Waterloo, Waterloo, Ontario, Canada.

A damage model is provided for a solid experiencing damage under deformation and pressure diffusion processes. Damage is coupled with pore pressure. Uniaxial compression test and analyses results compared for rock and concrete. Strain softening behavior appears to be predicted very well.

Applicability to cask impact: Probably not applicable. The model was developed for static loading and is in the development stage.

Dvorkin, Eduardo; N., Cuitiño; Alberto M., and Gioa, Gustavo; "A concrete material model based on non-associated plasticity and fracture;" Engineering Computations, Vol. 6, December 1989. Author affiliation: Instituto de Materials y Estructuras, Facultad de Ingenieria, Universidad de Buenos Aires, Argentina.

Concrete model presented. Model based on non-associated plasticity for the pre-failure and ductile post-failure regimes and fracture (smeared crack approach) for the brittle post-failure regime. 
Authors state that the model can describe concrete behavior under instantaneous multiaxial conditions.

Applicability to cask impact: Not applicable. Too much development is still needed.

Fichant, Stephanie; Pijauder-Cabot, Gilles; and La Borderie, Christian;

"Continuum Damage Modeling: Approximation of Crack Induced Anisotropy"; Mechanics Research Communications Vol. 24 No. 2 March-April 1997. Author affiliation: Laboratoire de Mecanique et Technologie, ENS Cachan, Universite P. et. M. Curie, France.

Authors state that continuum damage models applied to concrete and reinforced concrete are often based on simple assumption that cracking reduces the Young's modulus of the material. The decrease of Young' modulus is assumed to be proportional to the damage growth. Hence, the degraded material is isotropic in spite of any possible preferential orientation of the cracking.

A model is proposed which is based in part on the microplane model of Bazant and Ozbolt, in which the resulting damage is an anisotropic modification to the constitutive model.

Applicability to cask impact: Probably not applicable. Too much development still required to implement into DYNA.

Ghoicel, Dan M.; Wilson, Paul R.; Thomas, Gary, G.; Stevenson, John D.; "Structural Fragility Analysis Using Finite Element Computational Methods;" Probabilistic Mechanics and Structural and Geotechnical Reliability, Proceedings of the Specialty Conference Aug. 7-9 1996, ASCE. Author affiliation: Stevenson \& Associates, Cleveland, Ohio.

Analyses using ANSYS were run to evaluate shear failure modes of concrete cavity of reactor vessel under high-pressure impulsive load. Pressure load, prestressing forces and sectional capacities were modeled as random variables in a probabilistic evaluation using Advanced Mean Value (AMV) procedure.

Applicability to cask impact: Not applicable. Concrete modeling not specifically addressed.

Govindjee, Sanjay; Kay, Gregory J. and Simo, Juan C.; "Anisotropic Modelling and Numerical Simulation of Brittle Damage in Concrete;" International Journal for Numerical Methods in Engineering, Vol. 38, 1995. Author affiliation: Govindjee, Department of Civil Engineering, University of California, Berkeley, Kay, Department of Mechanical Engineering, Lawrence Livermore National Laboratory, Simo, Division of Applied Mechanics, Stanford University.

A model for continuum damage mechanics is presented, and its implementation into DYNA3D and NIKE3D is described. Analyses results are compared with test results for 
several notched simply supported concrete beam cases. The proposed model for concrete contains a minimal set of material constants, which can be determined from standard tests

Applicability to cask impact: Possibly applicable. Current use is for static problems.

Green, S. J. and Swanson, S. R.; "Static Constitutive Relations for Concrete," Technical Report No. AFWL-TR-72-244, April 1973, Air Force Weapons Laboratory, Kirland Air Force Base, New Mexico, obtained from National Technical Information Service, report no. AD-761 820. Author affiliation: TerraTek, Inc., Salt Lake City, Utah.

Report provides results of a test program on concrete samples generating results for both unconfined and confined 2.7 by 6 inch long solid cylinders. Compression and tensile stress-strain curves, compressive strength vs. aging time, principal stress-strain curves, deviatoric invariant stress-strain curves, mean normal stress vs., volume change curves, along with other data are provided. In addition, a numerical constitutive model, which might be included in a finite element code, is provided for concrete.

Applicability to cask impact: Applicable. In particular, the material parameters provided could be useful in cases where such data is needed and is not otherwise available.

Kotsovos, M .D. and Spiliopoulos, K. V., "Modelling of Crack Closure for FiniteElement Analysis of Structural Concrete," Computers and Structures Vol. 69, 1998. Author affiliation: National Technical University of Athens.

An existing finite element model of structural concrete is extended to allow for crack closure in localized regions of a structure. Analysis gives good fit to experimental values. Results demonstrate that compliance with Greek version of new European code of practice may cause rather than safeguard against brittle types of failure.

Applicability to cask impact: Not applicable. Primary benefit of crack closure algorithm is to loading occurring after the initial load that causes the crack. Our interest is in the peak decelerations resulting from the initial loading.

Labbane, M., E. C. Ting, and D. C. Sutton, "Computational Failure Analysis of Reinforced Plate Structures," Conference Proceedings, Mechanics Computing in the 1990's and Beyond, ASCE, Columbus Ohio, May 20-22, 1991. Author affiliation: School of Civil Engineering, Purdue University.

A plastic-fracture concrete model together with a smeared-layer reinforcement model is developed and described in this paper. The application is for a three-dimensional triangular plate element in a large displacement formulation; the plates are simply supported. The test results are compared with analyses and the load-deflection curve comparisons appear good.

Applicability to cask impact: Not directly applicable because they are testing and analyzing large deflection plate problem; the loading configuration and the results needed are quite different from our situation. 
Labbane, Mondher; Saha, Nripendra K.; Ting, Edward C.; "Yield Criterion and Loading Function for Concrete Plasticity;" International Journal of Solids and Structures, Vol. 30 No. 9 1993. Author affiliation: School of Civil Engineering, Purdue University.

Authors state, "Satisfactory concrete constitutive relations which have the capability of predicting general concrete structural behaviors are not available at this time."

Commonly used models are linear and nonlinear elastic models coupled (or not) with work-hardening plastic models. Plasticity based models have typically not been critically evaluated as to their accuracy and suitability for specific problems. Also, in the presence of high confining pressure the hardening behavior of concrete is difficult to model, since large volumetric strains dominate the concrete behavior under this condition.

A helpful review of functional forms describing concrete fracture surfaces is provided. Functions included in discussion are:

- von Mises

- Drucker - Prager

- Hsieh - Ting - Chen.

- William - Warnke

- Bresler - Pister

The authors undertook a seven year effort to develop software for the forms listed above and compared the results with published test data for uniaxial tension, biaxial tension, triaxial tension, and for split tension tests. A simply supported slab subjected to uniform loading was also evaluated. The material models were incorporated into two finite element codes (STRAW and SADCAT developed at Argonne National Laboratory. These codes were expanded and renamed, currently known as STRAWP and CBS-1 at Purdue, as part of the effort described in the paper.) Results of the evaluation are that Hsieh-Ting-Chen, William-Warnke, and Bresler-Pister methods have widely varying hardening rates under biaxial stress conditions: stiffer in biaxial compression, softer in tension-tension and tension-compression. Von Mises and Drucker-Prager functions exhibit nearly uniform hardening rate under all biaxial conditions. Under triaxial conditions, none of the considered functions accurately and consistently predicted the behavior of concrete.

Applicability to cask impact: Very useful background material. It is likely that the most critical segment of our cask on concrete slab impact problem occurs prior to crack formation - in which case the details about the failure surface are not as significant as they might be otherwise.

Li, Yuan N.; Muller, Michael; Worner, J. -D.; "Two New Methods of FictitiousCrack Model and their Applications;" Journal of Engineering Mechanics, Vol. 120,No. 12, December 1994. Author affiliation: Northwestern University.

Models for three-point beam bending with and without notches are presented. Ultimate load to failure is predicted. Test results are compared with finite element results. 
Applicability to cask impact: Not applicable. Beam bending and prediction of load to failure are addressed as opposed to cask impact.

\section{Loo, Yew-Chaye; and Guan, Hong; "Cracking and Punching Failure Analysis of RC Flat Plates;" Journal of Structural Engineering, Vol. 123, October 1997. Author affiliation: Griffith University.}

A strain-hardening plasticity model is developed for concrete. Reinforcement is included by adding its contributions to the material constitutive matrix that corresponds to the normal strain in the transverse direction. (This is a smeared model.) Study focuses on the implementation of a finite element model, which determines the deflection and punching shear strength at column connections of concrete plates. A discussion of strain hardening plasticity theory is included.

Nine half-scale reinforced concrete models, each weighing about $5000 \mathrm{~kg}$, were tested to failure. Results of tests were compared with presented model, and also with various "cookbook" procedures, including the American Concrete Institute method, the Standards Association of Australia procedure, and the recommendations of the British Standards Institution. (It is interesting to note that the ACl method produced the worst (most incorrect as well as nonconservative) results.)

Applicability to cask impact: Possibly applicable. Current use is for static problems.

Malvar, L. Javier; Crawford, John E.; Wesevich, James W.; Simons, Don; "A Plasticity Concrete Material Model for DYNA3D;" International Journal of Impact Engineering Vol. 19 No. 9-10 Oct-Nov 1997. Author affiliation: Karazogian \& Case, Glendale CA and Logicon RDA, Los Angeles, CA.

Authors state that DYNA3D includes several models which have been used by others to model concrete behavior, namely Material Model 5 (Soil and Crushable Foam), Material Model 16 (Concrete/Geologic Model), Material Model 17 (Isotropic Elastic-Plastic with Oriented Cracks), and Material Model 25 (Extended Two Invariant Geologic Cap). Authors state "Implementation of a realistic but efficient concrete model has proven complex and challenging." Tests sponsored by the Defense Special Weapons Agency provided an opportunity to revisit the existing material models in DYNA3D. Models suitable for representing concrete's constitutive behavior were assessed over the full range from elastic response to failure. The most robust model is Material Model 16; it contains several shortcomings, including the limitation of not incorporating shear dilation, which is observed with concrete.

The improved model includes a third, independent yield failure surface, removal of tensile cutoff and extension of the plasticity model in tension, and shift of the pressure cutoff.

Applicability to cask impact: Applicable. As a minimum, it provides a reference, which could be provided to users to help them determine needed parameters for Material Model 16 input. The described upgrade to the Material Model 16 would need to be benchmarked against the billet data 
Malvar, L. J.; Crawford, J. E.; Simons, D. A.; Wesevich, J. W.; “A Concrete Model for Dyna3D;" Proceedings of Engineering Mechanics May 21-24, 1995, ASCE. Author affiliation: Karazogian \& Case, Glendale CA and Logicon RDA, Los Angeles, CA.

The authors state that shortcoming of Material Model 16 in DYNA3D is that deviatoric response is decoupled from volumetric response. A model enhancement formulation is described. The conclusion states that model is significantly enhanced for behavior on a variety of stress paths.

Applicability to cask impact: Possibly very applicable. See above.

Marzouk, H. and Jiang, Dajiu, "Finite Element Evaluation of Shear Enhancement of High-Strength Concrete Plates," ACI Structural Journal, November-December 1996, American Concrete Institute. Author affiliation: Department of Civil Engineering at Memorial University of Newfoundland, Newfoundland, Canada and H. A. Simons, Vancouver, Canada.

Shear reinforcement types evaluated (e.g.: single-bend, U-stirrup, double-bend, shear stud, etc.) Reinforcement is included with a 1D-strain element overlaid on the brick mesh. Goal is to learn how best to design slabs to withstand punching shear failure.

Plasticity based concrete model implemented into ABAQUS. Model slightly overpredicted stress, under-predicted displacement.

Applicability to cask impact: Not directly applicable because we do not have shear reinforcement issues. Nevertheless, ABAQUS/Explicit model may be appropriate for cask impact problems.

Murakami, H.; Kendall, D. M.; and Valanis, K. C.; "A Nonlocal Elastic Damage Theory: Mesh Insensitivity Under Strain Softening;" Computers and Structures Vol. 48, No. 3, 1993. Author affiliation: Department of Applied Mechanics and Engineering Sciences, University of California at San Diego, and ENDOCHRONICS Inc., Vancouver, WA.

A method was presented for uniaxial wave propagation studies. 2D elements were developed and run. (Semi infinite bar problem.) Authors state in conclusions that this theory might be expanded to incorporate plastic damage processes to simulate the mechanical response of rocks, concrete and ceramics.

Applicability to cask impact: Not applicable. Too much development still needed..

Morandin, Greg D. and Nadeau, Eric, "Accident Impact of a Spent Fuel Dry Storage Package: Analytical/Experimental Comparison," American Society of Mechanical Engineers, Pressure Vessels and Piping Division, PVP Vol. 325, July 2126 1996. Author affiliation: Ontario Hydro Technologies, Etobicoke, Ontario, Canada. 
Analyses of a full scale DSC cask subjected to 9-meter CG over corner drop, a 1-meter drop of DSC the lid onto a pin, and 1-meter drop of the DSC welded flange region onto a pin are described. The DSC cask tested includes a polyurethane foam impact limiter and concrete shielding which is contained between steel inner and outer liners. The finite element code H3DMAP (an Ontario Hydro Research Division code) was used for the analyses. Tests were conducted of a half scale experimental model. Experimental decelerations were filtered at $1000 \mathrm{hz}$ because measurements of the natural container frequencies were in the $2000-3000 \mathrm{hz}$ range. A force-time-history plot is provided for one of the test/analysis comparisons and shows excellent agreement.

The concrete was modeled as an isotropic, hydrodynamic elastic-plastic material with an equation of state. Material properties were estimated from a variety of sources.

Applicability to cask impact: Possibly applicable. Because the cask evaluated included an impact limiter, the numerical difficulties in evaluating the concrete-cask impact decelerations are substantially lower than in a similar impact without a limiter.

Ozbolt, Josko and Bazant, Zdenek P., "Numerical Smeared Fracture Analysis: Nonlocal Microcrack Interaction Approach," International Journal for Numerical Methods in Engineering, Vol. 39, 1996. Author affiliation: Stuttgart University, Germany and Northwestern University, Evanston, IL.

The effect of microcrack interactions is addressed by implementing a new non-local method into an existing smeared-crack finite element code for concrete (not stated which code).

The peak load for tensile specimens is compared for the microcrack interaction method, and without this proposed method. The peak loads from the two methods match closely; however, the post peak behaviors do not match. The stated reason is that the material correctly softens as the microcracks coalesce into a single macrocrack.

Applicability to cask impact: Not applicable. Peak loads are shown to not change with the new method.

Prat, Pere C. and Bazant, Zdenek P., "Microplane Model for Triaxial Deformation of Saturated Cohesive Soils;" Journal of Geotechnical Engineering, Vol. 117, No. 6, June 1991. Author affiliation: Technical University of Cataluna, Barcelona, Spain and Northwestern University, Evanston, IL.

A microplane formulation for soils constitutive modeling is presented. Similar models for concrete behavior are described. In the case of concrete, the microplane may be thought of as representing the contact layers between hard aggregate particles in which most of the inelastic deformation (possibly including plastic slip) takes place.

The theoretical model is presented and may be introduced into a nonlinear FE code. 
Applicability to cask impact: While it appears from this paper that the model may be applicable, see paper by Ozbolt above. That later work suggests that the effect of the microplane model may not be relevant for cask impact.

Rashid, Y. R.; Nickell, R. E.; James, R. J.; Zhang, L.; "Validation of EPRI Methodology of Analysis of Spent-Fuel Cask Drop and Tipover Events;" Report \# TR-108760 prepared for Electric Power Research Institute, August 1997. Author affiliation: ANATECH Corp., San Diego, CA.

An empirical method is described which enables the user of the method to predict the deceleration of an ISFSI storage cask after impact onto a concrete storage pad. The authors state that "the fundamental assumption of the ... model is that . . . the damaging force can be estimated from the equivalent steady deceleration of the cask during prerebound impact."

Applicability to cask impact: Directly applicable, although it may oversimplify the problem. It is not a finite element method. Method must be benchmarked against the data in NUREG/CR-6608.

Simons, Donald A., "Concrete Material and Static Slab Responses in Several Independent Simulations," Workshop Proceedings: Recent Advances in Computational Structural Dynamics and High-Performance Computing, April 2426, 1996, edited by R. Namburu, Structures Laboratory, US Army Engineers Waterways Experiment Station, Vicksburg, MS. Author affiliation: Logicon R\&D Associates, Los Angeles, CA.

This paper summarizes a study in which four independent analyses address the same set of problems concerning concrete material modeling and static response of slabs. The Defense Nuclear Agency funded the study. The participating organizations were Weidlinger Associates (with in-house finite element code FLEX,) Aptek Inc. (with material model $\mathrm{xx}$ in DYNA3D, Karagozian \& Case (with modification to material model 16 in DYNA3D,) and Logicon R\&D Associates (also with a modification to Material Model 16 in DYNA3D).

Applicability to cask impact:Applicable because it describes the strengths and weaknesses of the codes.

III. Current Modeling Capabilities of Various Large Finite Element Codes: Utility for Modeling ISFSI Storage Cask Impacts

\section{ABAQUS/Explicit}

Two ABAQUS codes are available, ABAQUS/Standard and ABAQUS/Explicit. ABAQUS/Explicit is suitable for the impact problem considered in this report because the problem is dynamic. The concrete models available in the two versions differ considerably; only the concrete model in ABAQUS/Explicit is discussed here. ${ }^{4}$ 
The concrete model assumes that the compressive behavior is always linear elastic, and is therefore most accurate when brittle behavior dominates the problem. The model assumes that the material behavior prior to cracking is elastic. The model allows for removal of failed elements as an option. ABAQUS/Explicit uses a smeared crack model in orthogonal directions, and does not track micro-cracks. A variety of elements are available to be used with this material, including beam, shell, plane stress, plane strain, axisymmetric, and three-dimensional bricks.

Concrete material properties required include:

Shear modulus

Shear retention factor

Crack opening strain

Uniaxial tensile strength

Standard elastic material properties

\section{ANSYS}

ANSYS is an implicit code, which means that it is not ideal for dynamic impact problems. The ANSYS Multi-Physics option gives the user the option of using the MacNeal Schwendler MSC-DYNA, which is an explicit code more suitable for impact problems. Nevertheless, the concrete model in ANSYS implicit is discussed below.

ANSYS has an element called "SOLID65 3-D Reinforced Concrete Solid," which is an eight node brick element. Tensile cracking and compressive crushing are both possible. Tensile cracking is permitted in three orthogonal directions, is modeled as an adjustment of the material properties, and is smeared through the element. If an element fails in uniaxial, biaxial, or triaxial compression it is assumed to have crushed and no longer contributes to the stiffness of the element. Shear transfer coefficients may be input, allowing for a range between complete loss of shear transfer, (representing a smooth crack), or no loss of shear transfer, (representing a very rough crack). Steel-reinforcing may be included; if it is included, it is smeared throughout the element. One solid material and up to three steel-reinforcing materials may be specified for the element.

A sample beam bending problem is provided with an applied moment, with steelreinforcing included in the bottom quarter of the beam (in the tensile region.) The results are compared with expected results (it is not clear whether these are expected based on test results or another calculation) and the predicted depth of the crack is between 5 and 16 percent of the range of expected values. The predicted tensile and compressive stresses in the steel-reinforcing and concrete, respectively, are within 1 percent of the calculated values.

The excellent results demonstrated for the bending example problem are, however, not an indication of the suitability of this element for an impact problem. The metric for success for the impact problem is an accurate representation of the energy absorption capability of the concrete material, and a corresponding match in the deceleration of the billet upon impact. A benchmark analysis to test results would be desirable. 
Input required for concrete element properties (not including steel-reinforcing data):

Young's modulus in $\mathrm{x}$-direction

Coeff. of thermal expansion in $\mathrm{x}$-direction

Poisson's ratio in xy-plane

Mass density

Shear transfer coefficient for an open crack

Shear transfer coefficient for a closed crack

Uniaxial cracking stress

Uniaxial crushing stress

Biaxial crushing stress

Ambient hydrostatic stress state

Biaxial crushing stress under the ambient hydrostatic stress state

Uniaxial crushing stress under the ambient hydrostatic stress state

Stiffness multiplier for cracked tensile condition

\section{DYNA3D}

DYNA3D is a finite element code developed initially in the late 1970's at Lawrence Livermore National Laboratory, and has been available at nearly zero cost to the public for many years. Because it is aimed at developing dynamic finite element technology, commercial code developers incorporate ongoing changes in DYNA into commercial finite element codes. DYNA is the direct predecessor of Pam-Crash and Radioss, (both French codes,) MSC-DYNA and DYTRAN (MacNeal Schwendler codes), and LSDYNA (Livermore Software Technology code.) In addition, DYNA was used as a development resource for Pronto3D (Sandia National Laboratories code) and ABACUS Explicit (HKS code.) ${ }^{6}$

The use of DYNA3D for finite element analyses involving concrete is cited a number of times in the literature search summarized in Section Il of this report. Concrete researchers at LLNL and other national laboratories, in other countries, at universities, and in private research firms use DYNA3D.

The use of DYNA3D for the evaluation of the impact of ISFSI storage casks onto concrete pads is discussed in detail in NUREG/CR-6608. The principal shortcoming of about the use of Material Model 16 in DYNA3D is that the model requires extensive concrete input parameters, which make it cumbersome to use. It is for this reason that a parameter study is suggested in order to evaluate which of the parameters have a significant effect on the results and must be accurately determined, and which may be estimated based on known concrete properties.

\section{LS-DYNA3D}

As discussed above, LS-DYNA is a commercial version of DYNA3D, which has undergone separate development since 1991. LS-DYNA can be used to generate the results described in NUREG/CR-6608 using Material Model 16. Alternately, LS-DYNA may be linked with a model developed at AEA Technology known as the Winfrith 
Concrete Model, discussed in Section II of this report under Broadhouse, 1995. This Model is known as Material Type 84, and is not available in the version of LS-DYNA described in the May 1999 LS-DYNA user's manual. The sample problem described in the Broadhouse reference is an essentially fixed concrete plate impacted in the center with a dropped steel cylinder, discussed in greater detail in Broadhouse, 1992. For this sample case a sensitivity study was performed (described in Broadhouse, 1992) on the parameters required for the model to enable the best set of parameters to be combined in the final calculation. The crack patterns from the analysis and the test match fairly well, as do the deflection time history plots for selected nodes on the concrete. The deflection plots show that the peak deflection occurs at roughly 5 milliseconds, indicating that the impact is softer than those described in NUREG/CR-6608. Most of the benchmark details are not provided.

Concrete parameters required to run Material Type 84 in LS-DYNA are:

Tangent modulus

Poisson's ratio

Uniaxial compressive strength

Uniaxial tensile strength

Fracture energy

Aggregate size

Volumetric strain vs. pressure

\section{MARC}

MARC has the capability of analysis for low-tension capability materials such as concrete. Crack initiation, tension softening, plastic yielding, and crushing may be simulated. Steel reinforcement is included as a separate element with the same connectivity as the matrix element. ${ }^{7}$

Concrete material properties required include:

Young's modulus

Tension-softening Modulus

Yield stress

Critical cracking stress

Crushing strain

Shear retention factor

Poisson's ratio

\section{PRONTO3D}

PRONTO3D is a three- dimensional transient solid dynamics code for analyzing large deformations of nonlinear materials subjected to extremely high strain rates developed at Sandia National Laboratories. This Lagrangian finite element program uses an explicit time integration operator to integrate the equations of motion. A contact algorithm allows for the impact and interaction of deforming contact surfaces. The concrete model 
described for blast loading (see Attaway et. al., in Section II above) could very likely be used for the billet impact problem with success.

\section{Recommendations}

A number of researchers have commented that general purpose concrete models capable of modeling constitutive behavior of concrete under all loading conditions may not exist at this time. As a result, it is necessary to focus on the loading condition of interest. For the specific problem being addressed in this report, the concrete model needs to be able to represent the energy absorption capability of the concrete during impact conditions, so that the deceleration of a nearly rigid billet impacting the concrete material can be predicted. The behavior of concrete during the low velocity impacts in question is clearly inelastic (cracks are observed in the tests.) In general, inelastic behavior of concrete can be separated into two categories: (1) brittle failure in tension or compression (fracture or crush) and (2) internal slip and micro-cracking irreversible behavior (strain softening.) Both phenomena contribute to the energy absorption capability that must be represented.

Currently, the best test data available to provide ISFSI cask impact benchmarking, for any chosen method, are reported in NUREG/CR-6608. It must be noted that because the data presented in that report are for a roughly $1 / 3$-scale test of a solid billet, an extrapolation is required from the method presented to a full size cask. Nevertheless, until adequate full size data are available, any model that can predict the deceleration results for billet impact given in NUREG/CR-6608 must be considered reasonable.

The goal of finding a model that can adequately represent both the strain softening and brittle behavior of the concrete for impact conditions, with only a handful of easily obtainable parameters, is probably unrealistic. An alternative is to select what might be the best available finite element model, make logical estimates of the parameters which are difficult to obtain with standard concrete property tests, and then perform a sensitivity study to determine which of those parameters must be defined with a greater degree of accuracy.

Because ABAQUS/Explicit considers only elastic behavior in compression, the model may be too simplistic to adequately model the impact situation. On the other hand, since the goal is to match the deceleration of the billet or cask, the nonlinear compression behavior of concrete may not be relevant. MARC appears to have the needed capability, however, it was not cited in the references in Section II as a code that had been used for concrete impact calculations. ANSYS is an implicit code, which is not ideal for impact problems. PRONTO3D appears to have the capability, and has been benchmarked against dynamic loading conditions, although not the specific billet impact condition considered here. DYNA3D and LS-DYNA have been demonstrated by a number of researchers to be likely candidates for this analysis, however only DYNA3D has been benchmarked against the specific data available in NUREG/CR-6608.

Specific recommendations are as follows: 
- DYNA3D, LS-DYNA, and PRONTO3D appear to be the best finite element codes for the concrete impact problem being considered.

- If DYNA3D is used, evaluate the use of Material Type 45 (the Malvar model) for this problem. Select either Material Type 16 or 45.

- If LS-DYNA is used, attempt to obtain further information about the Winfrith Concrete Model to determine its suitability for this problem. Perhaps the developing organization, Winfrith Technology Centre would be willing to perform the benchmarks since they are attempting to market their software for analyses of this type. Then select among Material Types 16, 45, or the Winfrith Model (Type 84.)

- If PRONTO3D is used, evaluate the use of the modified Malvar model.

- Perform a study to determine which parameters in DYNA3D/Material Model 16 may specified within a broad range of estimated values, and which need to be specified more accurately.

- Allow cask applicants to use any code or method that can be benchmarked against the data in NUREG/CR-6608, or against data obtained by comparable testing. Ask the applicant to perform the benchmark.

- Eventually, perform a full-scale drop test onto a concrete storage pad in order to generate full-scale data for benchmarking.

\section{References}

1.Witte, M. et. al. "Summary and Evaluation of Low-Velocity Impact Tests of Solid Steel Billet Onto Concrete Pads," NUREG/CR-6608, UCRL-ID-129211, February 1998.

2.Whirley, R. G. "DYNA3D, A Nonlinear, Explicit, Three-Dimensional Finite Element Code for Solid and Structural Mechanics-User Manual," Lawrence Livermore National Laboratory, UCRL-MA-107254, Rev. 1, 1993.

3."LS-DYNA Keyword User's Manual Nonlinear Dynamic Analysis of Structures," Version 950, Livermore Software Technology Corporation, May 1999.

4. Fax pages from ABAQUS/Explicit User's Manual from Eric Weybrant, HKS technical Support, including pages 10.4.1-1 through 10.4.1-10.

5. Faxed copy of ANSYS information from Dr. M. Ozon, MCR Associates. Includes pg. 4-463 to 4-471 of ANSYS Elements Reference 001084, Tenth Edition, and pg. 146.1 to 146.2 of ANSYS Verification Manual 001095, $3^{\text {rd }}$ Edition. Also, pg. 14-259 to 14 268 of Volume IV of the ANSYS Theory Users Manual was used as a source. 
6. Walter, John W. and Bellshaw, David, "Survey to Determine the Value of DYNA," Lawrence Livermore National Laboratory, UCRL-ID-1 12607, January 1993.

7. Fax pages from MARC Material Library Volume A from Ed Rezler, MARC Technical Support, including pages 7-94 through 7-96 and Volume C 3-307. 